\title{
Kinetics and mechanism of oxidation of D-xylose and L-arabinose by chromium(VI) ions in perchloric acid medium
}

\author{
E. O. ODEBUNMI, A. I. OBIKE and S. O. OWALUDE *
}

Chemistry Department, University of Ilorin, P. M. B. 1515, Ilorin, Nigeria.

*Corresponding author, E-mail: owalude1412@yahoo.com

\begin{abstract}
The kinetics of oxidation of D-Xylose and L-Arabinose by $\mathrm{Cr}(\mathrm{VI})$ ions in perchloric acid medium have been investigated spectrophotometrically under pseudo-first-order conditions. The reactions exhibit first-order rate dependence each on the substrate and oxidant. The order with respect to $\left[\mathrm{H}^{+}\right]$is unity while no effect on the reaction rate is found with respect to the ionic strength. The Arrhenius $\left(\mathrm{E}_{\mathrm{a}}\right)$ and thermodynamic activation parameters $\left(\Delta \mathrm{H}^{\ddagger}, \Delta \mathrm{S}^{\ddagger}\right.$ and $\left.\Delta \mathrm{G}^{\ddagger}\right)$ are evaluated and the reaction mechanism is interpreted in terms of formation of a 1:1 intermediate complex between a protonated chromic acid molecule and a neutral sugar molecule in sharp contrast to the results of our earlier studies on the $\mathrm{C}_{6}$ and $\mathrm{C}_{12}$ sugars.

(C) 2009 International Formulae Group. All rights reserved.
\end{abstract}

Keywords: Kinetics, oxidation, D-xylose, L-arabinose, UV/visible spectrophotometry.

\section{INTRODUCTION}

Kinetics of the oxidation of carbohydrates has been given prominent attention in the past (Pigman, 1957; Krishna and Rao, 1995). This has been attributed to the fact that microbiological and physiological activities of carbohydrates is dependent on their redox behaviour (Khan et al., 2004). The study of mechanism of oxidation of sugars by different oxidizing agents is therefore of immense importance. Oxidation reactions have also been carried out in relation to structural elucidation, chemical degradation and mechanisms of action of oxidants (Odebunmi et al., 1999; Pandeeswaran et al., 2004; Shukla et al., 2004; Khan et al., 2006). These oxidation reactions have been carried out both in alkaline as well as in acidic media using such oxidants as metallic ions, inorganic acids, organometallic complexes and enzymes. Despite a large amount of data available, correlation of data is difficult due to variation in the reaction conditions employed in these reactions (Sen Gupta and Charterjee, 1984).
In continuation of our previous studies (Odebunmi et al., 1999; Odebunmi and Owalude, 2005), D-xylose and L-arabinose are selected to find out if the same mechanism is operative as in case of $\mathrm{C}_{6}$ and $\mathrm{C}_{12}$ sugars (Odebunmi and Owalude, 2005). This paper therefore describes the kinetics of oxidation of D-Xylose and L-Arabinose by $\mathrm{Cr}(\mathrm{VI})$ ions in perchloric acid medium at different ionic strength and temperature, and proposes a mechanism consistent with observed rate data.

\section{MATERIALS AND METHODS}

Chemical reagents

All the reagents were obtained from Aldrich chemicals and were used as received. Stock solutions of the sugars and $\mathrm{Cr}$ (VI) were prepared using deionised doubly distilled water.

\section{Spectra measurement}

Absorption spectrum of solutions of different concentrations of $\mathrm{Cr}(\mathrm{VI})$ was scanned from $300 \mathrm{~nm}$ in the UV region to 600 $\mathrm{nm}$ in the visible region. The kinetic data 
were collected at $371 \mathrm{~nm}$, the wavelength corresponding to maximum absorbance.

\section{Kinetic measurements}

The kinetic studies were carried out under pseudo-first-order conditions with the concentration of the sugars in large excess. All reactant solutions were placed in a thermostated water bath for one hour to attain the desired temperature of $40{ }^{\circ} \mathrm{C}$. Appropriate quantities of the reagent solutions were mixed in a $250 \mathrm{~cm}^{3}$ conical flask already placed in the thermostated bath. The reaction was monitored with Aquamate V4.60 UV-visible spectrophotometer by measuring the decrease in absorbance at $371 \mathrm{~nm}$, the reaction was completed when $\mathrm{Cr}(\mathrm{VI})$-sugar solution turned from yellow to green. The rate constants calculated were averages of two measurements. The results are generally reproducible within $\pm 2 \%$. (Upadhyay and Kambo, 2000).

\section{Test for free radicals}

A series of reaction mixtures containing the Chromium(VI) solution and each of the substrates was carried out under the exact kinetic conditions with the addition of $20 \%(\mathrm{w} / \mathrm{v})$ acrylamide. The reaction mixture was allowed to stand for 24 hours, no gel formation was noticed. Control experiments from which either $\mathrm{Cr}(\mathrm{VI})$ or aldose were excluded also produced no gel formation. These indicated that no free radicals were formed during these reactions (Sen Gupta and Basu, 1979a).

\section{Statistical analyses}

Statistical significance was determined using Duncan Multiple Range Test and values were considered statistically significant at $\mathrm{P}<0.05$ (Bewick et al., 2004).

\section{RESULTS AND DISCUSSION concentration}

Effect of variation of reactants

The pseudo-first-order rate constants $\left(\mathrm{k}_{\mathrm{obs}}\right)$ were determined (as the slope of a logarithmic plot of absorbance as a function of time) at different initial concentrations of the oxidant, but at constant initial concentration of the sugars, constant $\mathrm{pH}$, ionic strength, and temperature. The values of the $\mathrm{k}_{\mathrm{obs}}$ presented in table 1 indicate that the rate of the reaction was independent of the concentration of chromium(VI) for the two sugars, suggesting a first-order dependence of the reaction rate on Chromium(VI). (Sen Gupta and Basu, 1979a). In another set of experiments, the pseudo-first-order rate constants were measured at different initial sugar concentrations, but at constant initial concentration of $\mathrm{Cr}(\mathrm{VI}), \mathrm{pH}$, ionic strength and temperature, the results in table 2 show that $\mathrm{k}_{\mathrm{obs}}$ increased as the concentration of the sugars increased. The plots of $\mathrm{k}_{\mathrm{obs}}$ against [sugar $]_{\mathrm{o}}$ (Figure 1) were linear with a non zero intercept on the y-axis. The linearity of the plots up to $70 \%$ conversion confirms the firstorder depen-dence of rate of reaction on [sugar], (Lohdip et al., 1995). From the values of the second- order rate constants obtained, the relative reactivity of the sugars is Arabinose $>$ Xylose.

\section{Effect of variation of $\mathbf{p H}$}

The effects of variation of acidity at ionic strength of $0.2 \mathrm{M}$, maintained constant by the addition of $\mathrm{NaClO}_{4}$, constant initial concentrations of $\mathrm{Cr}(\mathrm{VI})$ and sugar at temperature of $40{ }^{\circ} \mathrm{C}$ on the pseudo-first order rate constants was measured. The rate of oxidation of the sugars increased with increasing acid concentration. The plot of log $\mathrm{k}_{\text {obs }}$ against $\log \left[\mathrm{HClO}_{4}\right]$ was linear (Figure 2), indicating that these reactions are acidcatalysed (Zucker and Hammet, 1939; Richard, 1970). The values of the slopes of the plots of $\log \mathrm{k}_{\mathrm{obs}}$ against $\log \left[\mathrm{H}^{+}\right]$are approximately 1 in each case; therefore the order with respect to $\left[\mathrm{H}^{+}\right]$for both sugars is unity.

\section{Effect of ionic strength}

The effect of different initial concentration of solutions of sodium perchlorate on the pseudo-first-order rate constants was investigated at constant concentration of sugar, $\mathrm{Cr}(\mathrm{VI})$, perchloric acid and temperature at $40{ }^{\circ} \mathrm{C}$. The reactions were found to be independent of the ionic strength (Table 3), indicating involvement of a neutral reactant molecule in the rate determining step (Bajpai et al., 1996).

\section{Effect of variation of temperature}

The oxidation reactions were carried out at different temperatures, but at constant concentrations of the sugars, $\mathrm{HClO}_{4}$, ionic 
Table 1: Variation of rate constant with chromium(VI) concentration at $40{ }^{\circ} \mathrm{C}$, $[$ SUGAR $]=1 \times 10^{-2} \mathrm{M},\left[\mathrm{HClO}_{4}\right]=2.4 \mathrm{M},\left[\mathrm{NaClO}_{4}\right]=1 \times 10^{-2} \mathrm{M}$.

\begin{tabular}{|c|c|c|c|c|}
\hline \multirow[t]{2}{*}[\mathrm{Cr}(\mathrm{VI})]{$\times 10^{-4} \mathrm{M}$} & \multicolumn{2}{|c|}{ Xylose } & \multicolumn{2}{|c|}{ Arabinose } \\
\hline & $k_{o b s} \times 10^{5} s^{-1}$ & $k_{2} M^{-1} s^{-1}$ & $k_{\text {obs }} \times 10^{5} s^{-1}$ & $k_{2} M^{-1} s^{-1}$ \\
\hline 1.00 & $1.40 \pm 0.48$ & $0.0014 \pm 0.29$ & $3.88 \pm 0.38$ & $0.0039 \pm 0.31$ \\
\hline 2.00 & $1.43 \pm 0.26$ & $0.0014 \pm 0.35$ & $2.25 \pm 0.28$ & $0.0023 \pm 0.28$ \\
\hline 3.00 & $1.78 \pm 0.45$ & $0.0015 \pm 0.45$ & $5.17 \pm 0.89$ & $0.0052 \pm 0.24$ \\
\hline 4.00 & $2.00 \pm 0.36$ & $0.0017 \pm 0.16$ & $4.94 \pm 0.61$ & $0.0049 \pm 0.53$ \\
\hline 5.00 & - & - & $6.50 \pm 0.52$ & $0.0065 \pm 0.48$ \\
\hline 6.00 & $1.53 \pm 0.52$ & $0.0017 \pm 0.39$ & $5.61 \pm 0.38$ & $0.0056 \pm 0.43$ \\
\hline 7.00 & $1.67 \pm 0.62$ & $0.0017 \pm 0.38$ & - & - \\
\hline
\end{tabular}

Table 2: Variation of rate constants with sugar concentration at $40{ }^{\circ} \mathrm{C},[\mathrm{Cr}(\mathrm{VI})]=5 \times 10^{-4} \mathrm{M}$, $\left[\mathrm{HClO}_{4}\right]=2.4 \mathrm{M},\left[\mathrm{NaClO}_{4}\right]=0.2 \mathrm{M}$.

\begin{tabular}{lcccc}
\hline [Sugar] $\mathbf{1 0} \mathbf{1 0}^{-\mathbf{2}} \mathbf{M}$ & \multicolumn{2}{c}{ Xylose } & \multicolumn{2}{c}{ Arabinose } \\
\cline { 2 - 5 } & $\mathbf{k}_{\mathbf{o b s}} \mathbf{x} \mathbf{1 0}^{\mathbf{5}} \mathbf{s}^{-1}$ & $\mathbf{k}_{\mathbf{2}} \mathbf{M}^{-1} \mathbf{s}^{-1}$ & $\mathbf{k}_{\mathbf{b b s}} \mathbf{x} \mathbf{1 0}^{\mathbf{5}} \mathbf{s}^{-1}$ & $\mathbf{k}_{\mathbf{2}} \mathbf{M}^{-1} \mathbf{s}^{-1}$ \\
\hline 1.00 & $1.67 \pm 0.20$ & $0.0017 \pm 0.51$ & - & - \\
1.20 & $1.80 \pm 0.19$ & $0.0015 \pm 0.32$ & $4.20 \pm 0.36$ & $0.0035 \pm 0.39$ \\
1.40 & - & - & $4.67 \pm 0.32$ & $0.0033 \pm 0.46$ \\
1.60 & $3.22 \pm 0.25$ & $0.0020 \pm 0.28$ & $6.00 \pm 0.48$ & $0.0038 \pm 0.26$ \\
1.80 & $3.40 \pm 0.36$ & $0.0019 \pm 0.36$ & $6.40 \pm 0.52$ & $0.0036 \pm 0.39$ \\
2.00 & $3.83 \pm 0.48$ & $0.0019 \pm 0.27$ & $7.93 \pm 0.38$ & $0.0040 \pm 0.41$ \\
2.20 & $4.22 \pm 0.39$ & $0.0019 \pm 0.65$ & $10.67 \pm 0.40$ & $0.0049 \pm 0.52$ \\
\hline \multicolumn{2}{c}{ Values are mean of at least 2 determinations + SD }
\end{tabular}

Table 3: Variation of rate constants with Sodium perchlorate concentration at $\mathrm{T}=40{ }^{\circ} \mathrm{C}$, $[\mathrm{Cr}(\mathrm{VI})]=5 \times 10^{-4} \mathrm{M},\left[\mathrm{HClO}_{4}\right]=2.4 \mathrm{M},[$ Sugar $]=1 \times 10^{-2} \mathrm{M}$.

\begin{tabular}{lcccc}
\hline$\left[\mathrm{NaClO}_{\mathbf{4}}\right] \mathbf{M}$ & \multicolumn{2}{c}{ Xylose } & \multicolumn{2}{c}{ Arabinose } \\
\cline { 2 - 5 } & $\mathbf{k}_{\text {obs }} \mathbf{x} \mathbf{1 0} \mathbf{s}^{-1}$ & $\mathbf{k}_{\mathbf{2}} \mathbf{M}^{-1} \mathbf{s}^{-1}$ & $\mathbf{k}_{\text {obs }} \mathbf{x} \mathbf{1 0}^{\mathbf{5}} \mathbf{s}^{-1}$ & $\mathbf{k}_{\mathbf{2}} \mathbf{M}^{-1} \mathbf{s}^{-1}$ \\
\hline 0.05 & $1.00 \pm 0.51$ & $0.0010 \pm 0.39$ & $3.42 \pm 0.62$ & $0.0034 \pm 0.63$ \\
0.08 & $1.13 \pm 0.52$ & $0.0011 \pm 0.56$ & $4.00 \pm 0.31$ & $0.0040 \pm 0.52$ \\
0.125 & $1.61 \pm 0.36$ & $0.0016 \pm 0.61$ & $4.71 \pm 0.29$ & $0.0047 \pm 0.39$ \\
0.15 & $1.23 \pm 0.29$ & $0.0017 \pm 0.62$ & $4.45 \pm 0.38$ & $0.0048 \pm 0.63$ \\
0.16 & $1.89 \pm 0.61$ & $0.0019 \pm 0.54$ & $4.81 \pm 0.65$ & $0.0048 \pm 0.62$ \\
0.20 & $2.00 \pm 0.63$ & $0.0020 \pm 0.48$ & $4.16 \pm 0.81$ & $0.0049 \pm 0.51$ \\
0.25 & $2.14 \pm 0.35$ & $0.0021 \pm 0.63$ & - & - \\
\hline \multicolumn{2}{c}{ Values are mean of at least 2 determinations \pm SD }
\end{tabular}

strength and chromium(VI). The plot of $\log \mathrm{k}_{2}$ as a function of temperature is linear for the two sugars (Figure 3) and the Arrhenius activation energies $\left(E_{a}\right)$ were determined from the slopes of the plots as presented in Table 4. The data showed that the Arrhenius activation energies for the oxidation of Xylose and Arabinose decreased in the order Arabinose > Xylose. The values of the thermodynamic activation parameters $\left(\Delta S^{\neq}, \Delta H^{\neq}\right.$, and $\left.\Delta G^{\neq}\right)$ (Table 4) were estimated following the literature procedure (Singh et al., 1991). The enthalpy of activation exhibited the same trend as was observed for the Arrhenius activation energy. The large negative values of entropy of activation for the two sugars indicate a rigid activated complex in the transition state (Khan and Abid, 2003). 


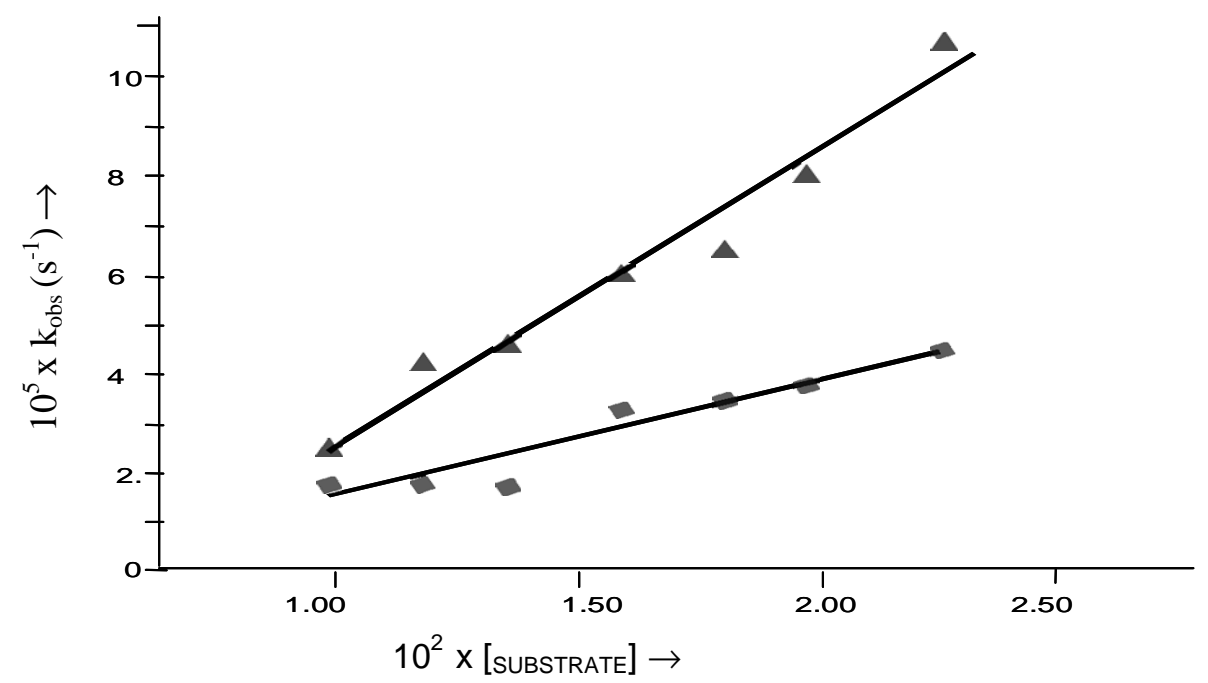

Figure 1: Plots of $\mathrm{k}_{\mathrm{obs}}$ against the sugar concentration at $40{ }^{\circ} \mathrm{C},\left[\mathrm{HClO}_{4}\right]=2.4 \mathrm{M},\left[\mathrm{NaClO}_{4}\right]=0.2 \mathrm{M}$, $[\mathrm{Cr}(\mathrm{VI})]=5 \times 10^{-4} \mathrm{M}$ for oxidation of $\mathrm{D}$-xylose and L-arabinose.

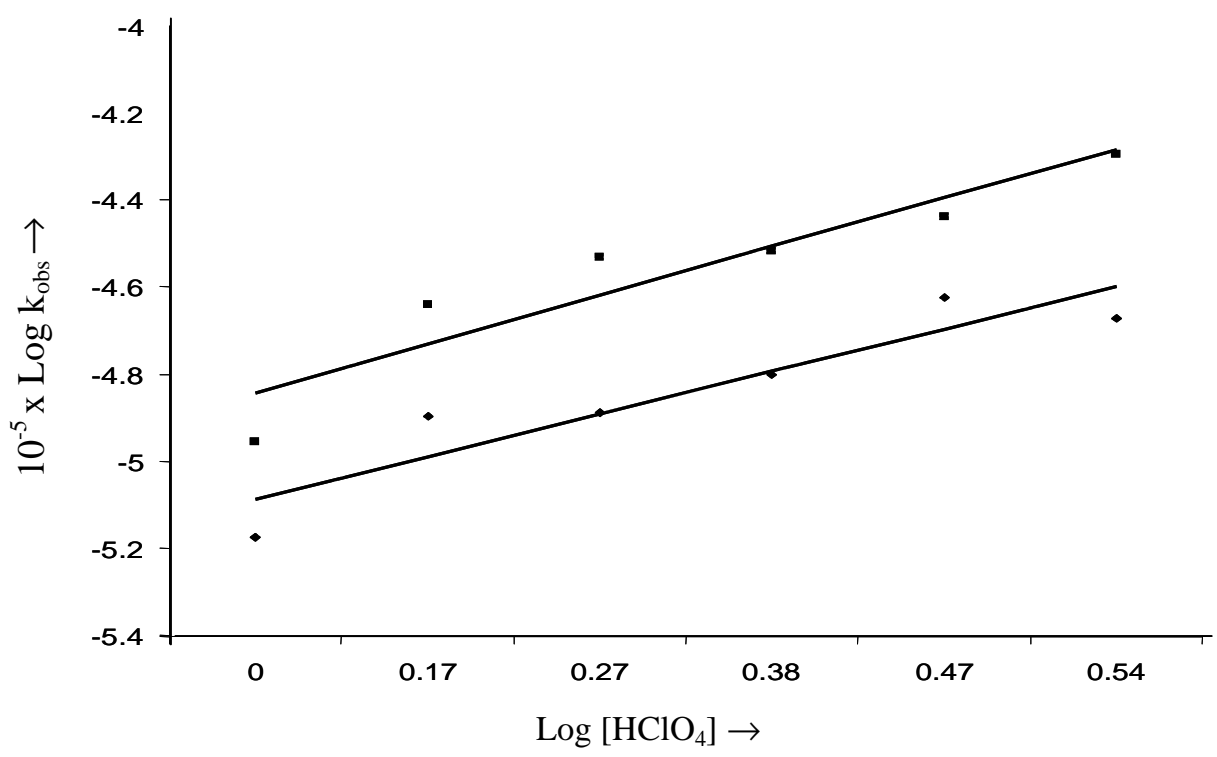

Figure 2: Zucker-Hammet plot for oxidation of D-xylose and L-arabinose.

$\square$ - D-xylose, - L-arabinose.

\section{Reaction mechanism and rate laws}

Similar values of the free energy change $\left(\Delta G^{\neq}\right)$obtained from this work is suggestive of a common mechanism for the oxidation of both aldopentoses (Bajpai et al., 1996). The double reciprocal plots of the pseudo-first-order rate constants against the sugar concentrations were linear (Figure 4), this provides ample evidence for the formation of a 1:1 intermediate complex between the oxidant and the sugars at the transition state (Singh et al., 1970; Odebunmi et al, 1999). The linear plots of $1 / \mathrm{k}_{\mathrm{obs}}$ against $1 /[\mathrm{S}]$ in Figure 4 is also an indication that the rate of the oxidation of these sugars is related to the substrate concentration by the relation 
Table 4: Activation parameters, complex formation and rate constant for disproportionation for the oxidation of sugars by chromium(VI) in perchloric acid medium at $313 \mathrm{k}$.

\begin{tabular}{|c|c|c|c|c|c|c|}
\hline Sugars & $\mathbf{E}_{\mathrm{a}} \mathrm{kJmol}^{-1}$ & $\Delta \mathbf{H}^{\mp} \mathbf{k J m o l}^{-1}$ & $\Delta \mathbf{S}^{\mp} \mathbf{J K}^{-1} \mathbf{m o l}^{-1}$ & $\Delta \mathbf{G}^{\neq} \mathbf{k J m o l}^{-1}$ & $\mathrm{~K}_{1} \mathbf{M}^{-1}$ & $\mathrm{k}_{\mathrm{s}} \times 10^{-4} \mathrm{~s}^{-1}$ \\
\hline Xylose & $49.70 \pm 0.5$ & $47.10 \pm 0.25$ & $-83.39 \pm 0.5$ & $73.20 \pm 0.5$ & 10.54 & 17.00 \\
\hline Arabinose & $51.81 \pm 0.5$ & $49.21 \pm 0.3$ & $-82.64 \pm 0.6$ & $75.08 \pm 0.25$ & 15.14 & 36.00 \\
\hline
\end{tabular}

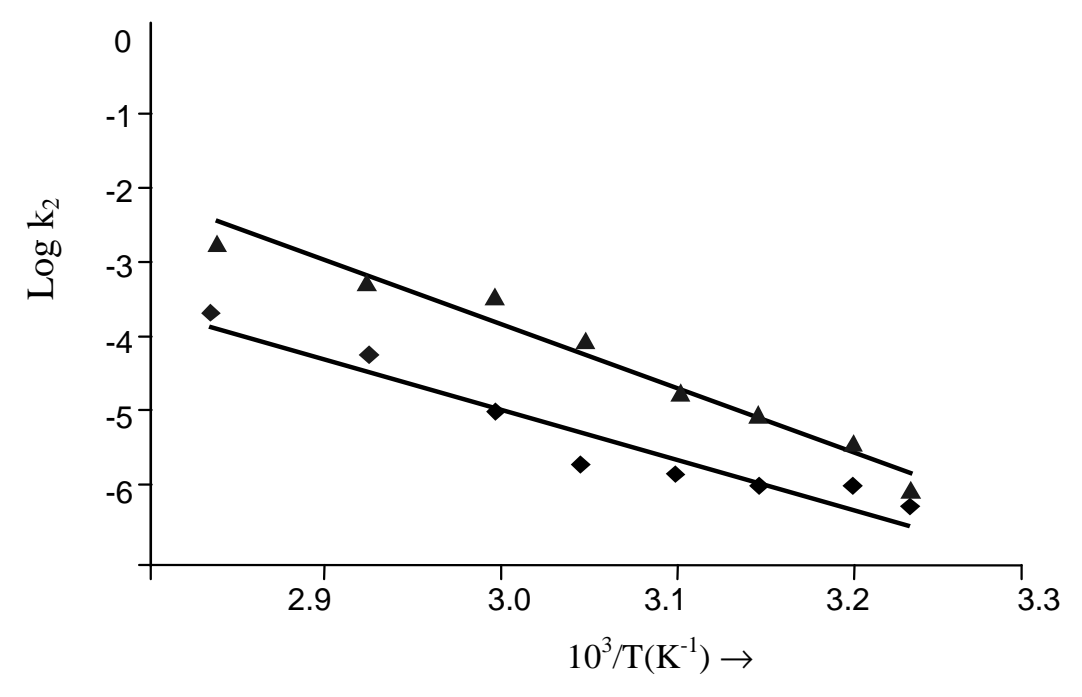

Figure 3: Arrhenius plot for oxidation of D-xylose and L-arabinose.

- D-xylose, $\Delta$-L-arabinose.

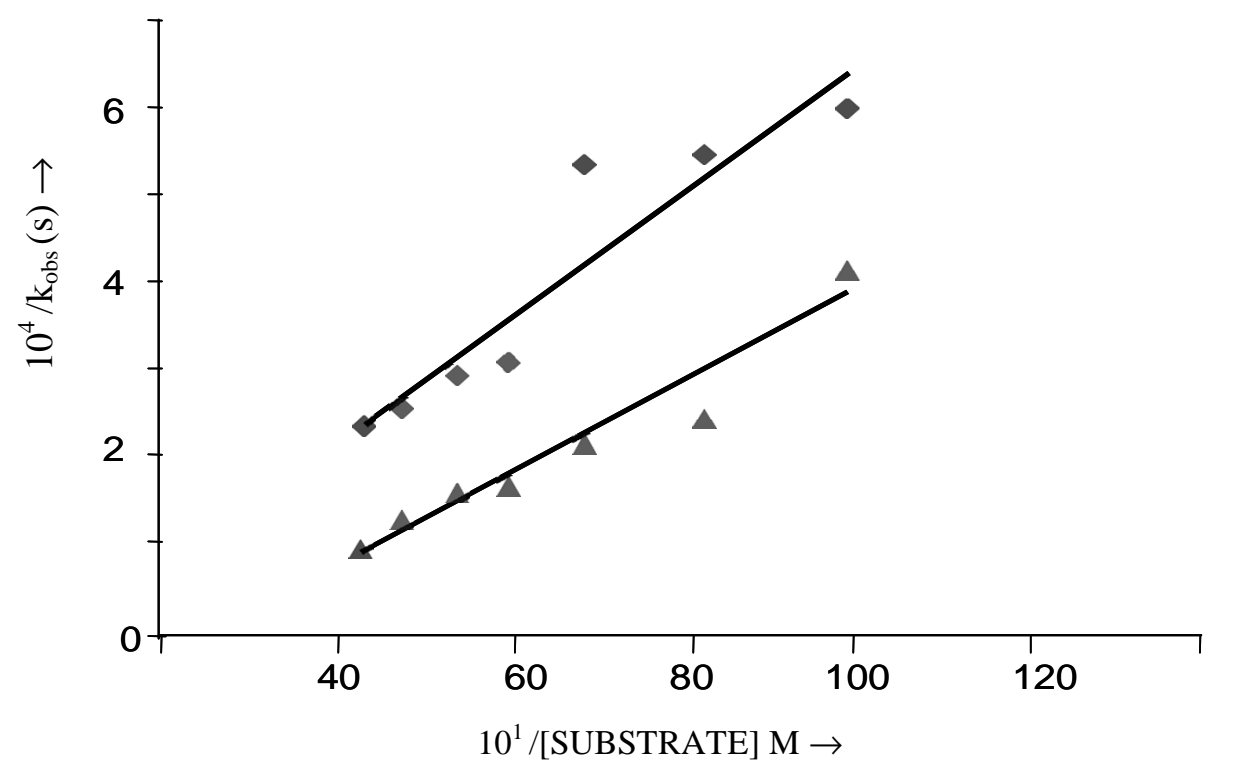

Figure 4: Double reciprocal plot $1 / \mathrm{k}_{\mathrm{obs}}$ against $1 /$ [SUBSTRATE] for oxidation of D-xylose and L-arabinose at $40{ }^{\circ} \mathrm{C}$. $\quad$-D-xylose, $\boldsymbol{\Delta}$-L-arabinose. 


$$
\frac{1}{k_{o b s}}=a\left(\frac{1}{[S]}\right)+b
$$

where $a$ and $b$ are the slope and intercept of the linear plot respectively (Dalal and Ram, 2001). It has been confirmed that the reactive specie of Chromium(VI) in acidic solution is $\mathrm{H}^{+} \mathrm{CrO}_{3}$ (Martinez et al., 1975). Based on our kinetic data and the literature evidence, the following reaction mechanism is proposed:

$$
\begin{aligned}
& \underset{(2)}{\mathrm{H}_{2} \mathrm{CrO}_{4}}+\mathrm{H}^{+} \underset{\mathrm{K}_{1}}{\rightleftharpoons} \mathrm{H}^{+} \mathrm{CrO}_{3}+\mathrm{H}_{2} \mathrm{O} \\
& \mathrm{H}^{+} \mathrm{CrO}_{3}+\mathrm{S} \underset{\mathrm{K}_{2}}{\rightleftharpoons}{ }^{\text {Complex }} \\
& \text { Complex }
\end{aligned}
$$

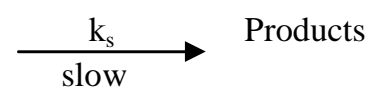

The protonated chromic acid which is the reactive specie reacts with a neutral sugar molecule to form the intermediate complex which then dissociates in a slow step to yield the products. In the mechanism of oxidation of $\mathrm{C}_{6}$ and $\mathrm{C}_{12}$ sugars, the reaction at the transition state was reported to occur between a protonated sugar molecule and protonated chromic acid molecule (Odebunmi and Owalude, 2005), a different trend is noticed with the $C_{5}$ sugars under the present study. The rate of the reactions in all cases were independent on the ionic strength of the medium, indicating that a neutral molecule is involved at the transition state in sharp contrast to the $\mathrm{C}_{6}$ and $\mathrm{C}_{12}$ sugars. This difference in mode of action of these two classes of sugars could therefore be explained in terms of their structural differences.

The aldopentoses and aldohexoses have been reported to exist only in furanoid and pyranoid forms with the latter being more stable (Gupta and Basu, 1979b). The stable pyranoid form exists mainly in chair conformations and these conformations provide the least strain and minimum Van dar Waals' repulsions (Neckers and Doyle, 1977). According to Pearson's hard and soft acidbase theory (Frost and Pearson, 1970), these sugars are hard bases therefore a rapid and reversible transfer of $\mathrm{H}^{+}$to the ring oxygen atom of the sugars is expected to occur in strong acidic medium as represented by the equation below (Gupta and Basu, 1979a).

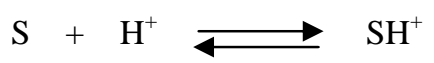

Aldopentoses with fewer than 6 carbons experience a kind of strain because the ring structure forces the carbon bonds into angles that are less than the normal $109.5^{\circ}$ angle, which represents the lowest energy configuration for the $\mathrm{sp}^{3}$ hybridized carbon atoms (Wade, 1999). This angle strain causes a higher potential energy and less stability. The $\mathrm{C}_{5}$ sugars under the present study because of their five member ring structure could only exist in the less stable furanoid form, therefore the ring strain and greater Van dar Waals' repulsions effects would make the protonation of their ring oxygen very difficult. So the reaction at the transition state of the $\mathrm{C}_{5}$ sugars will preferentially occur between the neutral sugar molecule and the protonated $\mathrm{Cr}(\mathrm{VI})$ ions. This also explains why these reactions of the $\mathrm{C}_{5}$ sugars did not go through a free radical mechanism as in the case of the $\mathrm{C}_{6}$ and $\mathrm{C}_{12}$ sugars (Odebunmi and Owalude, 2005). Equation 5 is thus applicable to $\mathrm{C}_{6}$ and $\mathrm{C}_{12}$ sugars only because of their six member ring structure.

The rate law derived from the above mechanism is

$\frac{-\mathrm{d}[\mathrm{Cr}(\mathrm{VI})]}{\mathrm{dt}}=\frac{\mathrm{k}_{\mathrm{s}} \mathrm{K}_{1} \mathrm{~K}_{2}\left[\mathrm{H}^{+}\right][\mathrm{S}]\left[\mathrm{H}_{2} \mathrm{CrO}_{4}\right]_{\mathrm{T}}}{1+\mathrm{K}_{1} \mathrm{~K}_{2}\left[\mathrm{H}^{+}\right][\mathrm{S}]}$

From which

$$
\mathrm{k}_{\mathrm{obs}}=\frac{\mathrm{k}_{\mathrm{s}} \mathrm{K}_{1} \mathrm{~K}_{2}\left[\mathrm{H}^{+}\right][\mathrm{S}]}{1+\mathrm{K}_{1} \mathrm{~K}_{2}\left[\mathrm{H}^{+}\right][\mathrm{S}]}
$$

Therefore

$$
\frac{1}{\mathrm{k}_{\mathrm{obs}}}=\frac{1}{\mathrm{k}_{\mathrm{s}} \mathrm{K}_{1} \mathrm{~K}_{2}\left[\mathrm{H}^{+}\right][\mathrm{S}]}+\frac{1}{\mathrm{k}_{\mathrm{s}}}
$$

From equation (7) above, it is evident that at sufficiently low substrate concentrations, the inequality $1>>\mathrm{K}_{1} \mathrm{~K}_{2}[\mathrm{~S}]\left[\mathrm{H}^{+}\right]$is valid and equation (7) reduces to: 
$\mathrm{k}_{\mathrm{obs}}=\mathrm{k}_{\mathrm{s}} \mathrm{K}_{1} \mathrm{~K}_{2}\left[\mathrm{H}^{+}\right][\mathrm{S}]$

Rate law (9) explains all the experimental results i.e. the first-order dependence of the reaction rate with respect to each, substrate, the oxidant as well as the $\mathrm{H}^{+}$. Equation (8) is also consistent with the plots in Figure 4.

\section{Conclusion}

From the observed kinetic data and the polymerisation test, the following conclusions can be drawn:

- The rate of the oxidation of D-xylose and Larabinose did not depend on the ionic strength of the medium of the reaction, indicating that a neutral molecule is involved at the transition state.

- This reaction did not go through a free radical mechanism as in the case of the $\mathrm{C}_{6}$ and $\mathrm{C}_{12}$ sugars.

- The observed negative value of entropy of activation for both D-xylose and L-arabinose supports the formation of a rigid activated complex as proposed in step II of the mechanism.

- The reaction mechanism involves formation of an intermediate complex between a protonated chromium(VI) ions and a neutral sugar molecule which dissociates in a slow step to give the products.

\section{REFERENCES}

Bajpai P, Shukla A, Upadhyay SK. 1996. $\mathrm{Pd}(\mathrm{II})$ inhibition during hexacyanoferrate(II) oxidation of sugars: A kinetic study. Int. J. Chem. Kin., 28: 413-419.

Bewick V, Cheek L, Ball J. 2004. Statistics review 9; One-way analysis of variance. Critical Care., 8: 130-136.

Dalal MK, Ram RN. 2001. Catalytic activity of polymer-bound Ru(III)-EDTA complex. Bull. Mater. Sci., 24: 237-241.

Frost AA, Pearson RG. 1970. Kinetics and Mechanism ( $1^{\text {st }}$ edn). Wiley: New York.

Khan Z, Abid M. 2003. The effect of complexing agents on the DMFchromium(VI) reaction: A kinetic Study. Trans. Metal Chem., 28: 79-84.

Khan Z, Babu PSS, Kabir-ud-Din. 2004. Kinetics and mechanism of oxidation of D-fructose by vanadium(V) in $\mathrm{H}_{2} \mathrm{SO}_{4}$ medium. Carbohydr. Res., 342: 133-140.

Khan Z, Ali MS, Kabir-ud-Din. 2006. Kinetics of the oxidative degradation of
D-xylose in the presence and absence of cationic and anionic surfactants. Colloid and Polymer Science, 284: 627-637.

Krishna KV, Rao PJ. 1995. Kinetics and mechanism of oxidation of some reducing aldoses by diperiodatoargentate (III) in alkaline medium. Trans. Metal Chem., 20: 344-346.

Lohdip YN, Iyun JF, Mitihir JI. 1995. Kinetics of the oxidation of formaldehyde by bromate ions in aqueous perchloric acid. Ghana J. Chem., 11: 465-469.

Martinez AM, Cushmac GE, Rocek J. 1975. Chromic acid oxidation of cyclopropanols. J. Amer. Chem. Soc., 97: 6502-6510.

Neckers DC, Doyle MP. 1977. Organic Chemistry $\left(1^{\text {st }}\right.$ edn). John Wiley \& Sons: New York.

Odebunmi EO, Oyetunji OA, Marufu H. 1999. The kinetics and mechanism of oxidation of D-mannose and D-mannitol by $\mathrm{KMnO}_{4}$ and Hexachloroiridiate (IV). Nig. J. Sci., 33: 145-154.

Odebunmi EO, Owalude SO. 2005. Kinetics and mechanism of oxidation of sugars by chromium(VI) in perchloric acid medium. J. Chem. Soc. Nig., 30: 187-191.

Pandeeswaran M, John B, Bhuvaneshwari DS, Elaugo KP. 2005. Kinetics and mechanism of oxidation of methionine by quinolinium chlorochromate. J. Serb. Chem. Soc., 70: 145-151.

Pigman W. 1957. The Carbohydrates: Chemistry, Biology and Physiology. Academic Press: New York.

Richard DG. 1970. Introduction to Physical Chemistry. Addison Wesley Publishing Company: London.

Sen Gupta KK, Basu SN. 1979. Kinetics and mechanism of oxidation of some aldoses by chromic acid in perchloric acid medium. Carbohydr. Res., (a) 71: 75 - 84 (b) 72: 139-149.

Sen Gupta KK, Charterjee U. 1984. Kinetics and mechanism of oxidation of Dglucose-6-phosphate by hexachloroiridate (IV) and tetrachloroaurate (III). Carbohydr. Res., 126: 321-325.

Shukla R, Sharma PK, Banerji KK. 2004. Kinetics and mechanism of the oxidation of some neutral and acidic $\alpha$-amino acids by tetrabutylammonium tribromide. $J$. Chem. Sci., 116: 101-106. 
Singh HS, Singh B, Singh AK. 1991. Mechanism of oxidation of reducing sugars by osmium tetraoxide in alkaline medium by the stopped - flow technique. Carbohydr. Res. 211: 235-243.

Singh SV, Saxena OC, Singh MP. 1970. Mechanism of oxidation of reducing sugars I: kinetics and mechanism of oxidation of D-xylose, D-glucose, Dfructose, D-mannose and mellibiose by copper(II) in alkaline medium. J. Amer. Chem. Soc., 92: 537-541.
Upadhyay SK, Kambo N. 2000. Kinetics and mechanism of the ruthenium(III) catalysed oxidation of reducing sugars by chloramine-T in alkaline medium. Trans. Metal Chem., 25: 461-464.

Wade LG. 1999. Organic Chemistry $\left(4^{\text {th }}\right.$ edn).Prentice Hall: New York.

Zucker L, Hammet LP. 1939. Kinetics of the iodination of Acetophenone in sulphuric and perchloric acid solutions. J. Amer. Chem. Soc., 61: 2791-2798. 